surgery for severe asymptomatic MR with preserved ejection fraction demonstrated that only $63 \%$ of patients received a mitral repair. ${ }^{5}$ Even amongst surgeons with the highest volume (ie, $>47$ mitral surgeries per year) the repair rate only reached $92 \% .^{5}$ Furthermore, in a propensity matched analysis, patients who underwent mitral replacement had a significantly higher mortality at 4 years $(12.1 \%$ vs $3.5 \% ; P<.001)$. A mortality rate of $12 \%$ at 4 years in patients without heart failure and with preserved LV function is startling. ${ }^{5}$ Even in the most experienced hands, a repair rate of $>95 \%$ appears to be difficult to achieve. Although excellent results with complex mitral valve repair have been reported, ${ }^{6}$ it would still be not easy to recommend mitral valve repair in all asymptomatic patients with severe mitral insufficiency. Or would it?

The current, thought-provoking study by Corporan and colleagues ${ }^{2}$ is timely and very important because it suggests that, at least in rats, irreversible myocardial remodeling may occur before a significant fall in ventricular ejection fraction. This appears to be a highly valuable observation for all of us to consider.

\section{References}

1. Quintana E, Suri RM, Thalji NM, Daly RC, Dearani JA, Burkhart HM, et al. Left ventricular dysfunction after mitral valve repair-the fallacy of "normal" preoperative myocardial function. J Thorac Cardiovasc Surg. 2014;148:2752-60.

2. Yuh DD. Commentary: Mitral repair in symptom-free patients with normal ventricles: becoming the new normal? J Thorac Cardiovasc Surg. 2019;157:1440-1.

3. Corporan D, Onohara D, Amedi A, Saadeh M, Guyton RA, Kumar S, et al. Hemodynamic and transcriptomic studies suggest early left ventricular dysfunction in a preclinical model of severe mitral regurgitation. J Thorac Cardiovasc Surg. 2021; 161:961-76.e22.

4. Nishimura RA, Otto CM, Bonow RO, Carabello BA, Erwin JP III, Fleisher LA, et al. 2017 AHA/ACC focused update of the 2014 AHA/ACC guideline for the management of patients with valvular heart disease: a report of the American College of Cardiology/American Heart Association task force on clinical practice guidelines. J Am Coll Cardiol. 2017;70:252-89.

5. Hannan EL, Samadashvili Z, Smith CR, Lahey SJ, Gold JP, Jordan D, et al. Mitral valve repair versus replacement for patients with preserved left ventricular function without heart failure symptoms. J Thorac Cardiovasc Surg. 2019;157: 1432-9.

6. David TE, David CM, Lafreniere-Roula M, Manlhiot C. Long-term outcomes of chordal replacement with expanded polytetrafluoroethylene sutures to repair mitral leaflet prolapse. J Thorac Cardiovasc Surg. 2020;160:385-94.

\title{
Commentary: The mitral matrix
}

\section{Tomasz A. Timek, MD, PhD}

Well-standardized mitral repair techniques have provided predictable and durable results for patients with degenerative mitral regurgitation, ${ }^{1}$ yet the timing of surgical intervention in asymptomatic patients continues to be debated. Current guidelines ${ }^{2}$ focus on left ventricular size and ejection fraction whereas some investigators suggest the use of more subtle markers such as left atrial volume index, ${ }^{3}$ myocardial strain, ${ }^{4}$ and circulating peptides ${ }^{5}$ in asymptomatic patients. Although watchful waiting with close surveillance has shown to be safe, fears arise that myocardial

\footnotetext{
From the Division of Cardiothoracic Surgery, Spectrum Health; and Michigan State University College of Human Medicine, Grand Rapids, Mich.

Disclosures: The author reported no conflicts of interest.

The Journal policy requires editors and reviewers to disclose conflicts of interest and to decline handling or reviewing manuscripts for which they may have a conflict of interest. The editors and reviewers of this article have no conflicts of interest.

Received for publication Sept 20, 2020; revisions received Sept 20, 2020; accepted for publication Sept 23, 2020; available ahead of print Sept 28, 2020.

Address for reprints: Tomasz A. Timek, MD, PhD, Division of Cardiothoracic Surgery, Spectrum Health, 100 Michigan Ave NE, Grand Rapids, MI 49503 (E-mail: tomasz.timek@spectrumhealth.org).

J Thorac Cardiovasc Surg 2021;161:979-80

0022-5223/\$36.00

Copyright (c) 2020 by The American Association for Thoracic Surgery

https://doi.org/10.1016/j.jtcvs.2020.09.087
}

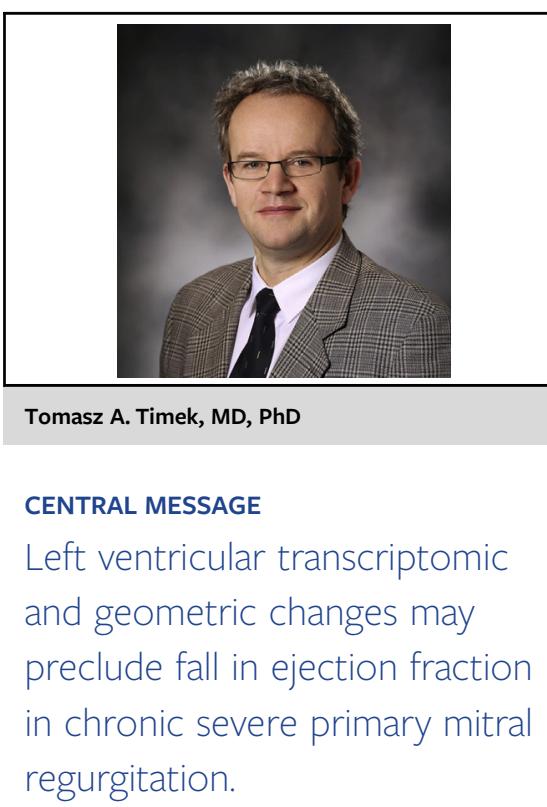

damage may be occurring even in the setting of preserved ventricular function.

Based on the experimental data presented by Corporan and colleagues ${ }^{6}$ in this issue of the Journal, these fears may not be unfounded. The investigators from Emory 
University performed an elegant hemodynamic and molecular study on rats induced with severe primary mitral regurgitation through guided disruption of the mitral valve with a $23-G$ needle. The animals were humanely killed at different time points to establish a longitudinal evolution of geometric and transcriptomic changes after induction of severe regurgitation. The authors found that left ventricular dilatation and transcriptomic changes occurred before a fall in ejection fraction, hence suggesting maintained myocardial performance may give a false sense of security when evaluating patients with severe mitral regurgitation.

Current clinical guidelines ${ }^{2}$ for treatment of severe primary mitral regurgitation recommend surgical repair when end-systolic diameter exceeds $40 \mathrm{~mm}$, and the presented experimental results corroborate these directives. Indeed, end-systolic volume increased significantly at about 10 weeks in the current experiment, offering the earliest geometric clue to myocardial dysfunction and may therefore be a better bellwether of watchful waiting than other echocardiographic parameters. However, it is the transcriptomic changes that deserve the greater attention. The authors demonstrate that as early as 2 weeks postinduction of mitral regurgitation there was a differential up- and down-regulation of genes versus sham-operated controls that persisted throughout the experiment. In the early phase, there was an upregulation of myocyte remodeling and oxidative stress pathways that precluded the fall in ejection fraction. These early cellular changes may offer a more sensitive guide for surgical intervention if they indeed represent a pathologic process.

Interpretation of the presented data must be tempered by the acute onset of severe mitral regurgitation, which is rarely seen in clinical practice. The compensatory mechanisms that are at work during the evolution of clinical degenerative mitral regurgitation may be overwhelmed or not functioning in the current scenario. As such, the presented changes may be an acute reactive response rather than a chronic adaptation, and in this hemodynamic environment, differential gene expression is difficult to interpret and caution should be used with clinical extrapolation. It is also unclear whether valve repair would have any effect on the reported transcriptomic changes. Clinically, however, recent data in more than 1000 patients undergoing degenerative mitral valve repair for severe mitral regurgitation ${ }^{7}$ revealed that surgery normalizes life expectancy to that of the general US population, suggesting that the deleterious milieu of severe mitral regurgitation is indeed reversible. Nonetheless, the study offers a glimpse into an aspect of the mitral universe not usually offered to the surgeon. The current genetic changes are painted in broad strokes, and further work is needed to identify the specific genes that are central to myocardial remodeling in the evolution of severe chronic mitral regurgitation. Whether a potential molecular trigger for optimal timing of surgical intervention exists remains to be explored.

\section{References}

1. Carpentier A. Cardiac valve surgery-the "French correction" J Thorac Cardiovasc Surg. 1983;86:323-37.

2. Nishimura RA, Otto CM, Bonow RO, Carabello BA, Erwin JP III, Fleisher LA, et al. 2017 AHA/ACC focused update of the 2014 AHA/ACC guideline for the management of patients with valvular heart disease: a report of the American College of Cardiology/American Heart Association task force on clinical practice guidelines. Circulation. 2017; 135:e1159-95.

3. Hu X, Jiang W, Li H, Yan G, Wang Y. Timing of valve repair for asymptomatic mitral regurgitation and preserved left ventricular function. Ann Thorac Surg. August 11, 2010 [Epub ahead of print].

4. Kislitsina ON, Thomas JD, Crawford E, Michel E, Kruse J, Liu M, et al. Predictors of left ventricular dysfunction after surgery for degenerative mitral regurgitation. Ann Thorac Surg. 2020;109:669-77.

5. Pizarro R, Bazzino OO, Oberti PF, Falconi M, Achilli F, Arias A, et al. Prospective validation of the prognostic usefulness of brain natriuretic peptide in asymptomatic patients with chronic severe mitral regurgitation. J Am Coll Cardiol. 2009; 54:1099-106.

6. Corporan D, Onohara D, Amendi A, Saadeh M, Guton RA, Kumar S, et al. Hemodynamic and transcriptomic studies suggest early left ventricular dysfunction in a preclinical model of severe mitral regurgitation. J Thorac Cardiovasc Surg. 2021; 161:961-76.e22.

7. Watt TMF, Brescia AA, Murray SL, Burn DA, Wisniewski A, Romano MA, et al. Degenerative mitral valve repair restores life expectancy. Ann Thorac Surg. 2020; 109:794-801. 